\section{Annual Lecture}

\section{REPORT OF THE 2000 ANNUAL LECTURE London, 15 March 2000.}

\section{The People's Network - cyberspace for the information age}

\section{Susi Woodhouse}

We were delighted to welcome Susi Woodhouse Network Adviser to the Library \& Information Commission [now Re:source: the Council for Museums, Archives and Libraries] - who gave a Power Point presentation summarising the genesis and present state of play of this huge network initiative.

The basic facts and plans are fully documented in formal reports and on the current updated website. Rather than attempt a formal record of the presentation this report consists of (a) some particularly interesting points made on the day as recorded by your editor and (b) an updated Progress Report kindly supplied for this number of LIRN by Susi Woodhouse.

\section{The speaker}

Since December 1999 Susi Woodhouse is one of two Senior Network Advisers in the People's Network Development Team working under the direction of Chris Batt [now Director of the Learning and Information Society Team at Re:source]. Originally employed in cataloguing in the British Library, she then moved to Ealing Public Libraries as Music Librarian. More recently she has worked for Westminster Public Libraries and for EARL - becoming more and more involved with IT projects and developments.

\section{Introduction}

The Project has backing from the highest quarter, witness this quotation from the Prime Minister:

Information is the key to the modern age. The new age of information offers possibilities for the future limited only by the boundaries of our imaginations. The potential for the new networks is beathtaking - the prospect of change as widespread and fundamental as the agricultural and industrial revolutions of earlier eras.

The networking of public libraries will place them is the forefront of the drive to create an educated, informed and ICT-literate society.

The original title New Library: the People's Netwark has been deliberately modified by removing the first two words. 'New' implied a shelf-life, which is not helpful. The scope is intended to be all embracing, not sector specific, to include libraries, museums, archives, public and community sectors. The brand name has to have lasting meaning and value.

\section{Objectives}

The mission is "to improve the quality of life for all citizens by facilitating the creation of the People's Network as a sustainable network of access points / learning centres that will provide a national gateway or channel co-ordinating all public sector information resources". There are three distinct objectives, of which the third is recognised as key to sustainability:

- Universal access to ICT equipment and services

- Access to training and lifelong learning opportunities

- Access to new, high quality, relevant electronic content and services

\section{Method}

The diverse programme of work includes:

- working with funding bodies

- providing information, advice and guidance

- lobbying for the sector

- forging cross-cutting partnerships [joined up working]

- action research, monitoring and evaluation

There are a range of funding sources and programmes for networking, and liaison work to ensure co-ordination is ongoing. 
Lobbying for the sector is important in linking into other initiatives such as: the wider networking agenda (NGfL and JANET included), Netful of Jewels, and the work of the Social Exclusion Unit, Capital Modernisation Fund, University for Industry and the Lord Chancellor's Office.

\section{What is the People's Network?}

First, it is a Physical Access Route with the target to connect all public libraries to the Internet by 2002 - with over 30,000 public access terminals. Government Funding via the New Opportunities Fund, on an altogether new scale, is available:

- $£ 100,000,000$ for hardware

- £50,000,000 for content creation

- £ 20,000,000 to train staff

In addition there is $\$ 4,000,000$ from the Gates Foundation to support access to ICT in areas of deprivation.

Second, the Network is to facilitate Cultural Development - with emphasis on creating access to UK museums, archives and libraries.

Third, the Network will act as a Channel for Service Integration - a means of drawing together all public knowledge and information - as is already being explored, for instance, in the 'SEAMLESS' and 'northeast.com' projects. The widespread vision here includes public service information at national and at local level, community information, as well as access to online local authority and Government. User needs and interest will be . paramount, and ease of access to information the driving force; users should not have to know who owns what.

\section{Useful URLs}

People's Network website at http://www.peoplesnetwork.gov.uk

National Grid for Learning at http://www.ngfl.gov.uk

New Opportunities Fund at http:/www.nof.gov.uk

EARL: the Consortium for Public Library Networking at http://www.earl.org.uk

\section{Discussion}

Access to the Network is envisaged both from public access points and from home. Authentication and user-profile building issues will need to be explored - smart card technology could offer potential solutions. There could always be the 'Login + Password' alternative. Development in this area was still ongoing.

The $£ 100$ million NOF Funding was part of the $£ 200$ million allocated by the Fund for its Community Access to Lifelong Learning programme. Details for the other $£ 100$ million were currently being worked out. The funds allocated should be sufficient to attain an identified minimum standard of infrastructure.

On access to materials for Lifelong Learning and the development of ICT learning centres it was important to ensure a consistent approach for the user, and for the various initiatives to work in a coherent way. 


\section{THE PEOPLE'S NETWORK: PROGRESS REPORT}

The People's Network represents the most comprehensive programme of public ICT provision so far supported by the Government and as such will deliver a network of access points with training support unmatched elsewhere in the UK. In two and a half years up to 30,000 terminals and associated hardware will be installed in libraries offering easy access for everyone to ICT equipment, learning opportunities, and new, high-quality electronic content and services.

\section{Infrastructure}

$£ 100 \mathrm{~m}$ is available to public libraries from the New Opportunities Fund Community Access to Lifelong Learning programme to implement People's Network infrastructure. The aim is to achieve equality of access across the country. Thus, every public library authority in the UK will receive funding to ensure comprehensive coverage. Allocations will be made to individual authorities on the basis of need. A slice of the infrastructure money will be set aside as a Challenge Fund to encourage targeted authorities to submit proposals for imaginative and innovative technical solutions to be delivered as part of the People's Network.

The result for UK citizens is that by 2002, there will be over 4,300 ICT learning centres based in public libraries, in the heart of local communities.

Translating $£ 100 \mathrm{~m}$ into something 'real on the ground' is not as straightforward as it may seem: there are many factors that need to be taken into account.

The first part of the process has been a data gathering exercise, examining what infrastructure is in place in each library authority. This has enabled an allocation to be calculated that refers directly to the number of publicly accessible Internet terminals that will be installed in individual libraries. Library authorities in England, Wales and Northern Ireland will be informed of their allocations at the end of July 2000. Allocations for Scotland will follow shortly after.

The second phase will require an implementation plan to show how each authority will ensure effective delivery of People's Network infrastructure to the specifications laid out. Although infrastructure allocations will be made on a local basis, the People's Network Development Team will encourage authorities to look at options for broadband connectivity on a regional (or subregional) basis. This will not only help to achieve economies of scale in purchasing network hardware and services, but will enable public libraries to retain a pivotal role as part of broader learning partnerships.

\section{Training}

Confident, experienced and fully trained library staff are key to the successful exploitation of resources available via the People's Network. The New Opportunities Fund $£ 20$ million ICT Training programme for public library staff will provide a workforce equipped both to use and help customers to use ICT tools to access information and services, and to support learners through interpretation and evaluation of resources.

80 percent of all local authorities will begin training this summer - a measure of the seriousness with which this programme is taken by library authorities, and far outstripping the estimated numbers at this stage.

Many training plans included innovative ideas, and, as a means of sharing best practice and supporting authorities throughout the training programme, we have extracted a number of these 'good ideas' and added them to the People's Network website (http://www.peoplesnetwork.gov.uk/training/bestpra ctice.html).

\section{Content creation}

The People's Network has an important role to play in developing and delivering cultural content to support lifelong learning and in contributing to a national cultural content strategy which will widen access through cyberspace to the rich tapestry of materials in our libraries, museums and archives in a consistent and coherent way.

The $£ 50$ million nof-digitise programme is a pathfinder for this, laying the foundations for others to build upon, providing that all-important critical mass. The building of a programme to create electronic resources across such a broad canvas has never been attempted previously, and as such has attracted interest from as far afield as Japan and the United States. 
The programme has now reached the second-stage bidding process, with some 250 organisations being invited to go forward. The Fund has decided to adopt a managed approach and will build on natural synergies between individual bids, clustering proposals into themed consortia. This has many obvious advantages: it avoids duplication of effort, employs economies of scale, it is cost effective in its use of resources both for applicants and the Fund. Above all, it offers the potential of a coherent and sustainable body of content which can be delivered, managed and developed in a consistent manner. Technical standards for the whole of the digital lifecycle are key to this, ensuring a common approach across the programme and with other electronic content initiatives such as UK Online, HE's DNER and the National and Regional Broadband Grids for Learning. The second stage will be completed by early 2001 and funding begin to flow in the Spring.

The People's Network also has a vital role to play in providing a channel of access to public services.

Public libraries are at the centre of their communities and the People's Network will deliver information services that are both local and national (or even global) at its very nerve ends. Egovernment via UK Online, local authority service and community information will all be available.

\section{Outcomes}

By the end of 2002 the People's Network project will have created 4,300 community ICT learning centres, one in every public library in the United Kingdom. Funded by the New Opportunities Fund, the project represents a significant element of the Government's plans to provide universal access to information and communications technologies in support of lifelong learning for everyone. It also ensures that the public library will continue to play a key role in the community, supporting its regeneration, development and continued wellbeing.

For further information, visit the People's Network website at

\section{http://www.peoplesnetwork.gov.uk}

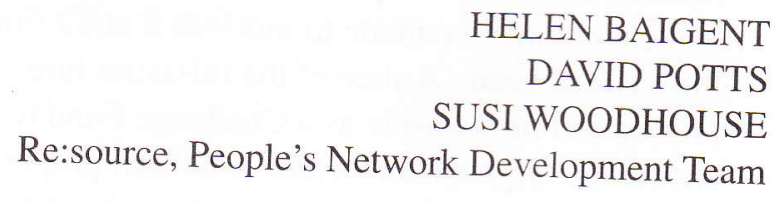

HELEN BAIGENT

SUSI WOODHOUSE

Re:source, People's Network Development Team

\section{PRIZE WINNERS at the Group's Annual General Meeting - March 2000}

(from left to right) Philip Payne (LIRG Chair); Elizabeth Gadd; Alwyn Jones; Alison Bremner; Jonathan
Back; Nicholas Lewis; Frances Boyle.

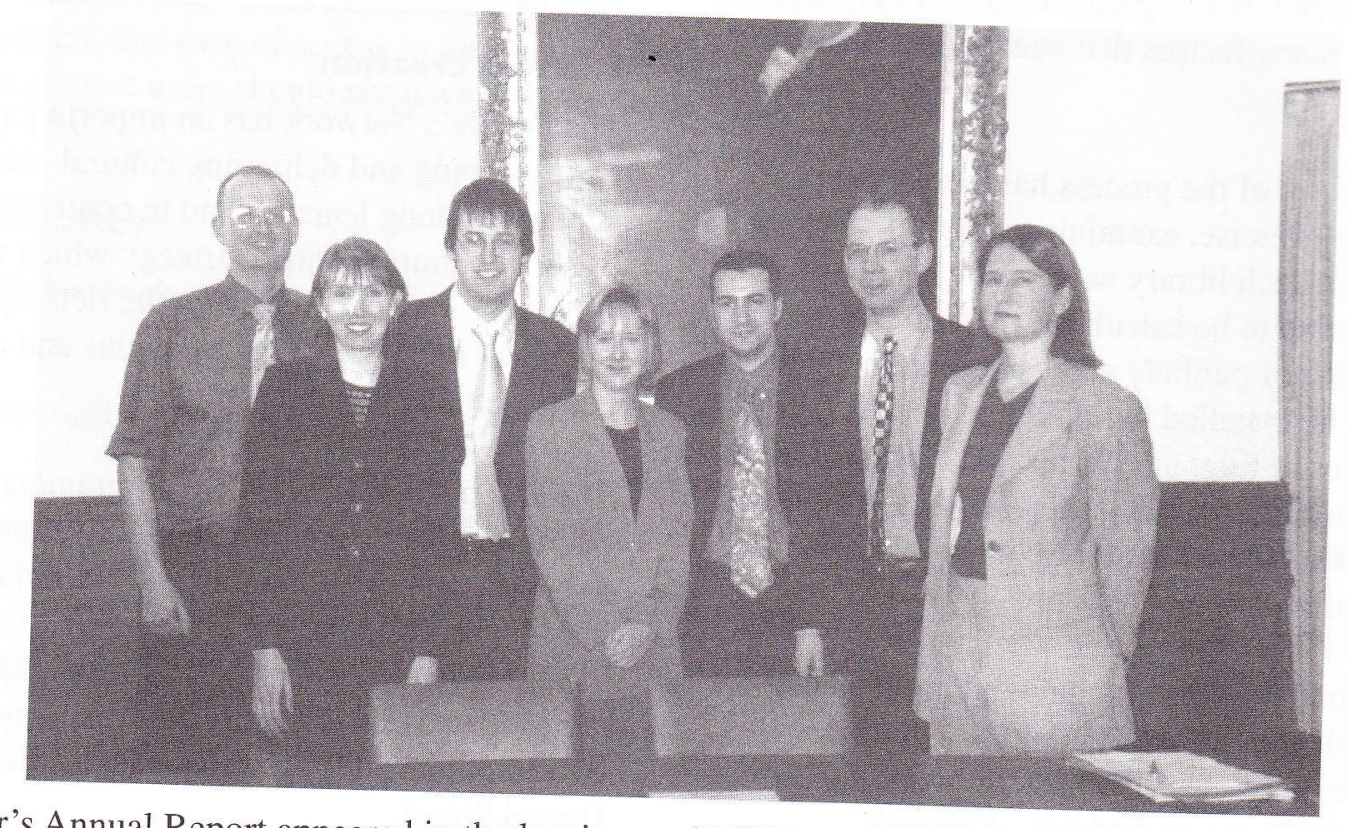

(The Chair's Annual Report appeared in the last issue of LIRN - number 76.) 